\title{
Physiochemically distinct SU-8 surfaces tailor Xylella fastidiosa cell-surface holdfast and colonization
}

Silambarasan Anbumani ${ }^{1}$, Aldeliane M. da Silva, ${ }^{1}$ Andrei Alaferdov ${ }^{2}$, Marcos V. Puydinger dos Santos ${ }^{1}$, Isis G. B. Carvalho ${ }^{3}$, Mariana de Souza e Silva ${ }^{3}$, Stanislav Moshkalev ${ }^{2}$, Hernandes F. Carvalho ${ }^{4}$, Alessandra A. de Souza ${ }^{3}$, and Monica A. Cotta*

${ }^{1}$ Institute of Physics “Gleb Wataghin”, University of Campinas-13083-859 Campinas, São Paulo, Brazil

${ }^{2}$ Center for Semiconductor Components and Nanotechnologies, University of Campinas, Campinas, SP, 13083-870, Brazil

${ }^{3}$ Citrus Center APTA "Sylvio Moreira" Agronomic Institute of Campinas 13490-970 Cordeirópolis, São Paulo, Brazil

${ }^{4}$ Department of Structural and Functional Biology, Institute of Biology, University of Campinas, 13083-862, Campinas, São Paulo, Brazil

*Corresponding author:

Silambarasan Anbumani, Email: kavianbuarasu@gmail.com. Tel: +91 8883396916

Monica A. Cotta, Email: monica@ifi.unicamp.br; Tel: +55- 19-35215338. Fax: + 55-1935215376.

\begin{abstract}
:
SU-8 polymer is an excellent platform for diverse applications due to its high aspect ratio of micro/nanostructures fabrication and exceptional optical, chemical, and biocompatible properties. Although SU-8 has been often investigated for a variety of biological applications, how its surface properties influence both the interaction of bacterial cells with the substrate and its colonization is poorly understood. In this work, we tailor SU-8 nanoscale surface properties to investigate single cell motility, adhesion and successive colonization of a phytopathogenic bacteria, Xylella fastidiosa. Different surface
\end{abstract}


properties of SU-8 thin films have been prepared using photolithography processing and oxygen plasma treatment. We found a significant difference in bacterial cell behavior and subsequent colonization on SU-8 as surface property changes. A larger density of carboxyl groups in hydrophilic plasma-treated SU-8 surfaces promotes faster cell motility in the earlier stage of the growth. The hydrophobic nature of pristine SU-8 surfaces has no trackable bacterial motility with 5 to 10 times more single cells adhered to surface than its plasma-treated counterpart. In fact, plasma-treated SU-8 samples suppressed bacterial adhesion, with surfaces showing less than $5 \%$ coverage. These results not only showcase that SU-8 surface properties can impact the bacterial behavior in a spatiotemporal manner, but also provide insights on the prominent ability of pathogens to evolve and adapt to different surface properties.

KEYWORDS: SU-8 polymer, surface carboxylic groups, surface motility, Xylella fastidiosa, bacterial adhesion, biofilm formation.

\section{Introduction}

The development of portable, high-throughput and cost-effective healthcare and medical devices is indebted to substantial advances in materials. The SU-8 epoxy polymer is one such material that has great potential for fabrication of high aspect ratio of micro/nanostructured scaffolds for lab-on-a-chip devices[1-4]. In particular, SU-8 has been used as an impressive platform for the development of various smart biomedical devices including biosensors [5-7], bacterial diagnosis[8-10], cantilever[11], bioelectrodes[12] and microrobots $[13,14]$ owing to its excellent optical and mechanical properties with chemical stability even against acids[3,15,16]. Moreover, SU-8 nanostructures with tunable high aspect ratios have been fabricated and used for eukaryote cell interface and for simultaneous visualization of the traction force and focal adhesion of eukaryotic cells[17]. Whilst the SU-8 properties combined with its biocompatibility facilitates its application in bio-related material interfaces[6-9,17,18], how the surface properties of SU-8 affect bacterial adhesion and successive proliferation is poorly understood.

The evolution of bacteria relies on several survival strategies and as a collective response of multicellular assembly[19,20]. Specifically, the virulence of a pathogenic 
bacteria depends on its capability to attach to biotic and abiotic surfaces [21-23]. Interaction between bacteria and material surfaces can be affected by various properties of the material surface, including wettability (hydrophobic or hydrophilic), surface energy and chemistry, charge, elastic modulus, topography, and so on [21,24-27]. An in-depth understanding of the physicochemical aspects of bacterial-substratum interface is important both fundamentally and clinically for preventing microbial adhesion and consequently, biofilm infections [20,26-29]. Moreover, the development of in vitro models to unraveling the spatiotemporal relationship to bacterial adhesion, cell motility and subsequent colonization has remained a key topic in biomedical research[22,30].

Here, we investigate the in vitro cell motility, adhesion, and biofilm formation in the early-stage bacterial life cycle of Xylella fastidiosa with the different surface properties of SU-8. X. fastidiosa is a gram-negative phytopathogen that causes diseases worldwide in important crops (e.g. citrus, grape, coffee, almond, olives, among others); the bacteria colonizes two distinct habitats: xylem vessels of host plants, and the foregut of xylemfeeding insects which are transmission vectors [31]. In particular, the entire biofilm formation process, starting from single cell adhesion, has been investigated, turning $X$. fastidiosa into a reliable bacterial model[24,32]. This species is also interesting as it shares many genetic traits with other human bacteria [33,34] and has relatively slow duplication time ( $\sim 6$ h) [30], which renders easier the observation of surface colonization. Moreover, $X$. fastidiosa relies on type-IV pili, which are about 2-to-6- $\mu \mathrm{m}$ long, for twitching motility; these pili are significantly impacted by surface chemistry[35,36]. The twitching motility governed by type IV pili is used to colonize different surfaces and play a crucial role in the development of biofilms of $X$. fastidiosa $[35,36]$ as well as of several other Gram-negative bacteria [37-39].

In this work, different wettability and surface chemical modification of SU-8 samples have been achieved using UV illumination, and oxygen plasma treatment, to explore the characteristics of bacterial-SU-8 surface interfaces. Atomic Force Microscopy (AFM), contact angle measurements and X-Ray Photoelectron Spectroscopy (XPS) were used to evaluate nanoscale surface properties. The bacteria-surface interaction and its relation to the nanoscale surface properties of the samples is investigated by monitoring cell motility, adhesion and microcolonies formation using confocal laser scanning microscopy 
(CLSM) for different time intervals $(6,12$, and 24 hours) of growth, under identical environments. The mean velocity, net displacement and mean square displacement (MSD) of single cell trajectories have been extracted from cell tracking information for different samples. We found that carboxylic functional surfaces resulted in straighter trajectories with faster-moving cells, for shorter times of observation. The hydrophobic surface of pristine SU-8 leads to relatively absence of cell movement while a larger number of cells adhered to surface. Furthermore, the influence of physiochemically distinct surfaces in the development of microcolonies of the bacteria has been studied.

\section{Experimental section}

\subsection{Sample preparation}

SU-8 monomer films deposited by spin coating are exposed to UV illumination so that a polymer film of thickness of about $300 \mathrm{~nm}$ was obtained. For all bacterial adhesion experiments carried out in this work, the samples were cleaned to remove inorganic as well as organic contamination. For the preparation of oxygen plasma-treated samples, a radio frequency (RF) plasma generator (PLASMA Technology SE80, Model ACG 5) operating at frequency of $13.56 \mathrm{MHz}$ and base pressure of 1 mTorr was used with the following treatment conditions. During treatment, $\mathrm{O}_{2}$ gas flow of $50 \mathrm{sccm}$ at a pressure of approximately $100 \mathrm{mTorr}$ and plasma power of $100 \mathrm{~W}$ was maintained for treatment times of 60 seconds in $\mathrm{O}_{2}$ flow. The detailed optimization of the treatment time is given elsewhere [5]. In addition to SU-8 samples, flat InP substrates are also used for comparison. The substrates were cleaned with acetone, isopropanol, and deionized water, and dried with a gentle nitrogen flow. The InP substrates were further cleaned by oxygen plasma using $\mathrm{O}_{2}$ gas flow of $50 \mathrm{sccm}$ at a pressure of approximately 100 mTorr and plasma power of $200 \mathrm{~W}$ was maintained for 10 minutes in $\mathrm{O}_{2}$ flow. To generate carboxylic-acid-modified InP surfaces, initially the oxygen plasma cleaned samples has been incubated in DMSO (dimethyl sulfoxide) containing 5M Ethanolamine hydrochloride for overnight. Then the samples were washing using DI water and further PEGylated by depositing $2 \mathrm{mM}$ of amino-reactive, heterobifunctional NHS-PEG-COOH (MW 3.400, LaysanBio, USA)[40]. After the functionalization process, the supports were rinsed three times in water and dried 
with $\mathrm{N}_{2}$ gas. For all bacterial growth experiments, the substrates were sterilized by UV lamp in the biosafety hood (VECO Biosafe A1) immediately prior to the experiment.

\subsection{Surface characterization}

\subsubsection{Surface Topography}

Keysight (model 5500) scanning atomic force microscopy (AFM) with intermittent contact mode (AC mode) using the cantilever of a nominal stiffness of $3 \mathrm{~N} / \mathrm{m}$ was used to record the surface topography of samples. Root mean square (RMS) surface roughness of the samples was extracted from the topography images with $0.7 \mathrm{X} 0.7 \mu \mathrm{m}^{2}$ area using Gwydion (version 2.56) software.

\subsubsection{Contact angle}

Static water contact angle of each surface was measured using sessile drop contact angle measurement method[5,41]. For each sample, three measurements were performed at ambient temperature of approximately $(25 \pm 2){ }^{\circ} \mathrm{C}$ and relative humidity ranging from $50 \%$ to $70 \%$. For the samples incubated in PW media, the surface contact angle was determined after brief rinse with DI water followed by drying with a gentle nitrogen flow.

\subsubsection{XPS measurement}

The analysis of surface chemical groups was performed using X-ray photoelectron spectroscopy (XPS). XPS experiments were carried out on a SPECS system (SPECS $\mathrm{GmbH}$, Germany) equipped XR 50 - X-ray source with Al Ko radiation ( $h v=1486.6$ eV) and Phoibos 100 hemispherical energy analyzer with MCD-9 detector. The X-ray anode was run at $100 \mathrm{~W}$ and the high voltage was kept at $10.0 \mathrm{kV}$ with sample normal polar angle of tilt of $20^{\circ}$. The pass energy was fixed at $20.0 \mathrm{eV}$ to ensure sufficient sensitivity. The base pressure of the analyzer chamber was about $3 \times 10^{-10} \mathrm{mbar}$.

The quantitative analysis was performed in program CasaXPS (Version 2.3.16Dev52). The $\mathrm{C}_{1 \mathrm{~s}}$ lines were investigated in detail. In order to establish the type of chemical bond between carbon and oxygen atoms, deconvolution of these lines was performed using the program PeakFit v 4.06 (PeakFit $^{\mathrm{TM}}$ ). The data were fitted by Voigt 
functions using method "I-residuals" for detection of hidden peaks after performing a Shirley background subtraction.

\subsection{Bacterial growth}

Green fluorescent protein (GFP) expressing strain 11399 of Xylella fastidiosa subsp. pauca bacteria was used in this study[42]. Bacterial inoculum with a concentration of $1 \times 10^{7} \mathrm{CFU} / \mathrm{mL}\left(\mathrm{OD}_{600} 0.5\right)$ from the pre-inoculum was used for the experiments as initial concentration for bacterial growth studies in PW broth media[43]. Bacteria extraction and pre-inoculum preparation was described elsewhere[32,42]. The SU-8 and InP samples were incubated for different growth times (specified in the respective manuscript text) in a bacterial stove (410/3NDR, Nova Ética, Brazil) at $28^{\circ} \mathrm{C}$ without culture media replacement.

\subsection{Image acquisition using Confocal microscopy}

For in-vitro studies, the samples were placed inside a Teflon dish (10 mm diameter and 5 $\mathrm{mm}$ in height). Then, $400 \mu \mathrm{L}$ of inoculum was injected inside the Teflon dish, which was covered with a sterilized borosilicate cover glass. The assembly was incubated inside a bacterial oven at $28^{\circ} \mathrm{C}$. The bacterial growth on the various samples were studied using confocal laser scanning microscope (CLSM) (Carl Zeiss AG, Germany) operated with 40x water-immersion objective (Plan-Apochromat, NA. 1.0, Zeiss). Each sample has been studied at 6,12, 24 hours of growth (the samples were stored back inside a bacterial oven at $28{ }^{\circ} \mathrm{C}$ for more hours after each observation). The exposure times and lamp intensity were kept optimal to reduce photobleaching and phototoxicity. X. fastidiosa cell motility on the surface were recorded using time-lapse movies acquired in every two second interval for 1 to 5 minutes. For quantification of cell attachment and colonization to the surfaces, 2D images were collected at separate fields of view of $210 \times 210 \mu \mathrm{m}^{2}$ for each sample.

\subsection{Image analysis}

The area of bacterial biofilms was extracted from raw fluorescence images, and 3D rendered images were created using Carl Zeiss Zen (3.0 SR) software. The image backgrounds were subtracted using the built-in rolling-ball background subtraction algorithm in ImageJ software. The cell movement trajectories were tracked on these 
different samples using tracking algorithm provided in Track mate plugin in ImageJ according to the methodology described by Tinevez et.al $[44,45]$. Laplacian of Gaussian filter was applied to detect single cells, and estimated blob diameter and threshold were fixed for the optimum detection of cells in each data collection.

Net track displacement values, which represent the length of a straight line that extends from the first to the last spot of a track, and mean velocity values, which provides the average of the velocity between successive spots over all the spots of a track, have been extracted from the cell tracking information[44] of the CLSM images. The angle between successive $(\mathrm{x}, \mathrm{y})$ coordinates (segments) of the tracks is calculated to investigate the orientation of the tracks. Furthermore, to explore positional freedom which the bacteria experience, mean square displacement (MSD) as a function of time has been calculated from Isy software using the track information[46]. The MSD describes the average of the squared distances between the starting and ending position of a cell movement for all time$\operatorname{lags}(\Delta \mathrm{t})$ within a trajectory.

\subsection{Statistics}

All data are presented as mean value \pm standard deviation. The statistical significance between different groups has been accessed by resulting from two-tailed, unpaired t-tests. A $p$-value smaller than 0.05 was considered as statistically significant. Number of asterisks on figures indicate data statistical significance level $(* p<0.05 ; * * p<0.01$; $* * * p<0.001$; n.s. $=$ non-significant).

\section{Results and Discussion}

Despite the SU-8 surface being inherently hydrophobic, which is undesired for most biological applications, the modification of surface properties such as wettability and surface functional groups can be employed by means of dry and wet treatment processes $[5,7,47,48]$. To evaluate the surface properties, we chose SU-8 pristine and oxygen plasma treated (for 60 seconds) SU-8 samples, based on our optimized protocol for surface modifications that provides minimal surface roughness[5]. In addition, flat Indium Phosphide (InP) substrates are also chosen for reference control since the X. fastidiosa bacterial adhesion to InP surfaces has been well studied[49,50]. Initially, RMS surface 
roughness (Fig. 1A) was characterized from AFM topography images (Fig. S1), and contact angle measurements were used to study surface wettability of the InP, pristine and plasma-treated SU-8 samples (Fig. 1B). The results show that pristine SU-8 and InP samples have relatively small surface roughness $(<0.5 \mathrm{~nm})$ and a more hydrophobic nature (contact angle $>65 \square$ ). On the other hand, plasma treatment of SU-8 surfaces provided an increase in the surface roughness features $(\sim 1.5 \mathrm{~nm})$ and a highly hydrophilic nature as compared to the pristine surface.

The surface functional groups of the SU-8 samples were characterized by XPS (Fig. 1C and D). Using data represented in literature [51-58] the few components of $C_{1 s}$ peak found after deconvolution procedure can be assigned. Components located at 283.6- 283.9 $\mathrm{eV}$ and $284.3 \mathrm{eV}$ are associated with non-oxygenated carbon bounded atoms in pentagon and heptagon rings $(\mathrm{C}-\mathrm{C})$ bonded and $\mathrm{sp}^{2}$ carbon $(\mathrm{C}=\mathrm{C})$ conformations. Components at 285.4-286.0 eV, 287.0 - $287.6 \mathrm{eV}$ and $288.3 \mathrm{eV}$ are attributed to $\mathrm{C}$-atoms bonded to $\mathrm{O}$ in ethers group $(\mathrm{C}-\mathrm{OH}), \mathrm{C}$ in epoxy groups $(\mathrm{C}-\mathrm{O}-\mathrm{C})$, and carbon bonded to two oxygen atoms in carbonyl groups $(\mathrm{C}=\mathrm{O})$, respectively. It should be noted that the plasma-treated samples showed a component at 288.4-289.5 eV that represents carboxylate $(\mathrm{O}-\mathrm{C}=\mathrm{O})$ groups. Moreover, one broad component was detected at a high-energy region (peak near 292-293 $\mathrm{eV}$ ) usually associated with $\pi$ - $\pi^{*}$ electrons transition processes[59,60]. A comparison of the components areas which are proportional to the amount of the chemical bonds is shown in Table 1 for pristine and plasma treated SU-8 samples. These results quantitatively confirm that pristine samples present surface epoxy groups. In the case of plasma-treated samples, an additional surface carboxylic group was observed[5]. 

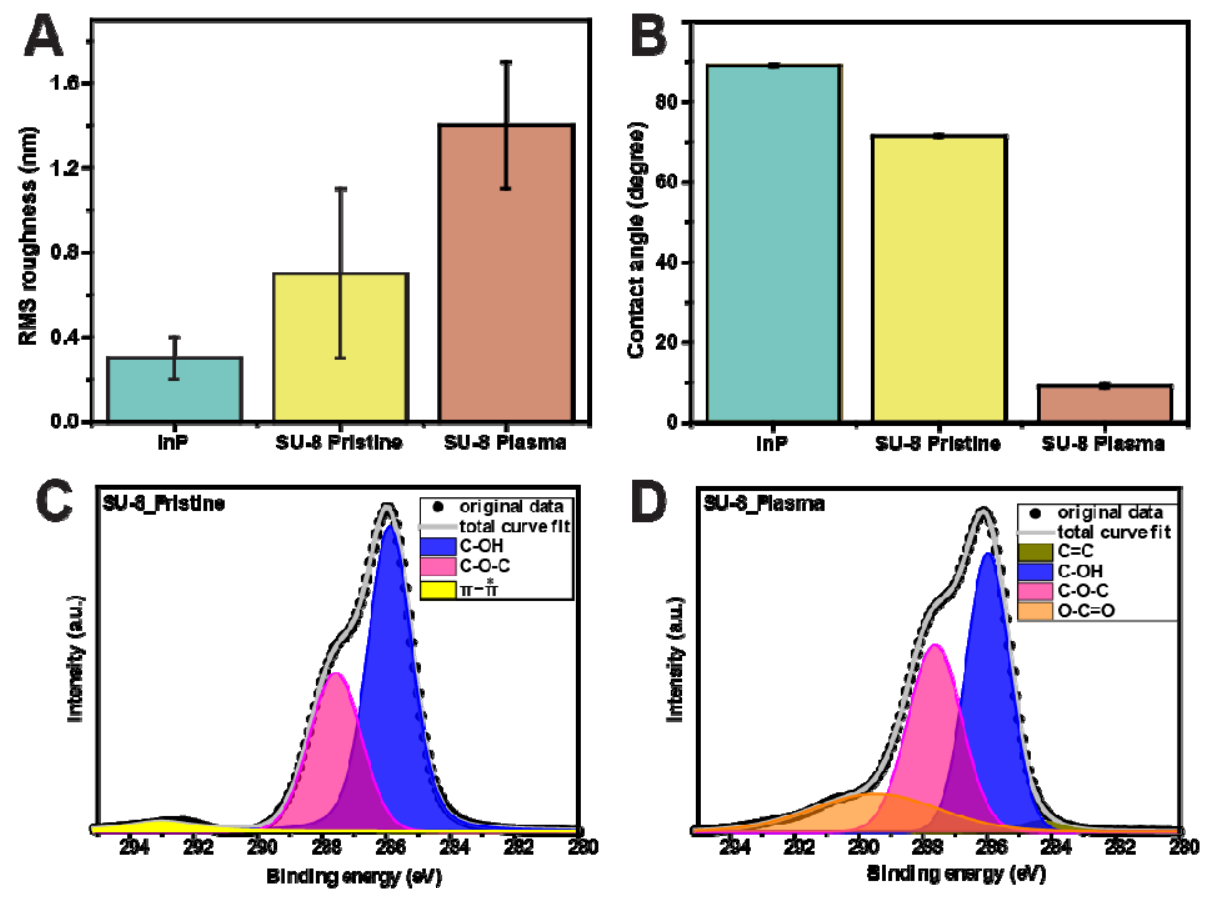

Figure 1. Surface physicochemical characterization of SU-8 polymer. (A) RMS roughness measurements extracted from AFM topography images and (B) contact angle of InP, SU-8 pristine and SU-8 plasma-treated samples. Deconvoluted $\mathrm{C}_{1 \mathrm{~s}}$ peaks of XPS spectrum of (C) pristine and (D) plasma-treated samples.

Table:1 Comparison of the $C_{1 s}$ peak components area of pristine and plasma-treated SU-8 surfaces obtained from XPS spectra.

\begin{tabular}{|l|l|l|l|l|l|}
\hline \multirow{2}{*}{ Surface } & \multicolumn{4}{|l|}{ Area of $\mathrm{C}_{1 \mathrm{~s}}$ peak components (in \%) } \\
\cline { 2 - 6 } & C-C & C-O-C & C-OH & O-C=O & $\pi-\pi^{*}$ peak \\
\hline SU-8 pristine & absent & 34.5 & 62.2 & absent & 3.3 \\
\hline SU-8 plasma & 1.9 & 36.5 & 44 & 17.6 & absent \\
\hline
\end{tabular}

In order to investigate the surface wetting properties of the samples, the contact angle has been measured after incubating the samples in PW growth media (Table 2) that we used later for the bacterial growth. The pristine SU-8 surfaces remained hydrophobic until $6 \mathrm{~h}$ of incubation. For longer incubation times (12 and $24 \mathrm{~h})$ the surface becomes moderately hydrophilic. Interestingly, the plasma-treated surface still maintains its 
hydrophilic nature even after $24 \mathrm{~h}$ incubation time, while InP surfaces show moderate hydrophilic behavior for all three different incubated times. The SU-8 samples of distinct surface wettability (hydrophobic and hydrophilic) properties with the enhanced surface carboxylic groups have been extended next to investigate the $X$. fastidiosa bacterial growth experiments along with comparison to the InP samples.

Table 2. Contact angle measurements of SU-8 and InP surfaces, after incubation in PW media for 6, 12 and $24 \mathrm{~h}$.

\begin{tabular}{|l|l|l|l|}
\hline \multirow{2}{*}{ Surface } & \multicolumn{3}{|l|}{ Contact angle after incubating the samples in PW media for } \\
\cline { 2 - 4 } & $\mathbf{6} \mathbf{h}$ & $\mathbf{1 2} \mathbf{~}$ & $\mathbf{2 4} \mathbf{~ h}$ \\
\hline InP & $53 \pm 0.5$ & $48.8 \pm 0.9$ & $49 \pm 2.0$ \\
\hline SU-8 pristine & $81.5 \pm 1.9$ & $51.3 \pm 1.6$ & $53 \pm 0.5$ \\
\hline SU-8 plasma treated & $24.4 \pm 1.5$ & $23.7 \pm 0.8$ & $38.8 \pm 1.3$ \\
\hline
\end{tabular}

$X$. fastidiosa bacterial growth experiments have been studied using CLSM for the interval of 6, 12 and $24 \mathrm{~h}$ growth time. Initially, we monitored the bacterial motility from time-lapse videos by tracking the motion of each cell on InP, SU-8 pristine and plasmatreated surfaces prepared according to protocols mentioned in the methods section. Fig. 2 (A-C) shows trajectories (in yellow) of motile single cells after 6 hours of growth. Plasmatreated samples have comparatively straighter and longer moving cell trajectories up to $6 \mathrm{~h}$ (Fig. 2B). However, for longer growth times (12 and $24 \mathrm{~h}$ ) of these samples and all growth times of pristine InP samples, trajectories presented random orientations and curly type, associated with twitching motility (Fig. 2A \& Fig. S2). Surprisingly, the hydrophobic pristine SU-8 samples show absolutely no trackable moving cells; instead, more adherent single cells than the plasma treated SU-8 and InP samples are present, even after a prolonged growth time (24h) (Fig. 2C). The cells irreversibly adhered to pristine SU-8 surfaces within the first contact (Video S1); strongly adhered cells make it difficult to capture the cell trajectory on the surface for the observation time windows used here. 
Mean velocity and orientation of cell trajectories is acquired from cell tracking information. The comparison of continuous time intervals of 1,3 and 5 minutes and different locations (Fig. S3) on plasma-treated SU-8 samples after 6 h of growth, confirm no significant differences in the mean velocity $(\sim 0.5 \mu \mathrm{m} / \mathrm{s})$ associated with the time interval and different location of the measurements. Therefore, mean velocity and displacement values for $3 \mathrm{~min}$ of tracking events have been extracted and analyzed by statistical comparison. After 6 hours of growth, the average cell motility on plasma-treated SU-8 surfaces is significantly higher $(\sim 0.56 \mu \mathrm{m} / \mathrm{s})$ than the mean velocity of later grown samples (12 and 24h) and all three-growth times of InP surfaces as well $(\sim 0.5 \mu \mathrm{m} / \mathrm{s})$ (Fig. 2D). The average cell velocity of about $0.5 \mu \mathrm{m} / \mathrm{sec}(\sim 30 \mu \mathrm{m} / \mathrm{min})$ of the cells moving on these surfaces is comparable with previously reported mean velocity of X. fastidiosa ( 25 $\mu \mathrm{m} / \mathrm{min}$ ) studied under no-flow condition in microfluidic chambers[35]. The individual segments of each trajectory were calculated from the xy coordinates extracted from tracking information for the plasma-treated surface (Fig. 2E). Positive angles are two times larger than negative after $6 \mathrm{~h}$ growth, which confirms the straighter orientation of the cells (Fig. 2E \&Table S1), while 12 and $24 \mathrm{~h}$ samples have almost the same movement for both ranges of the angle distribution histograms. 


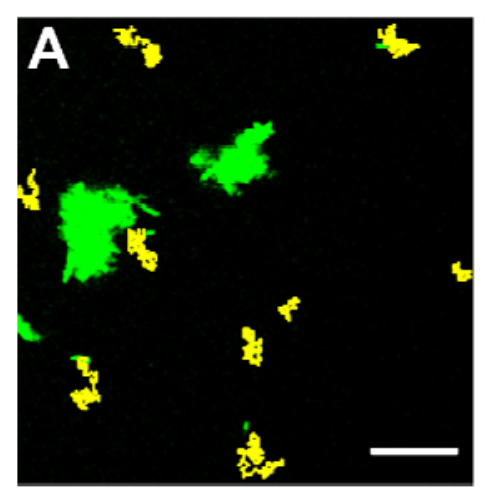

D

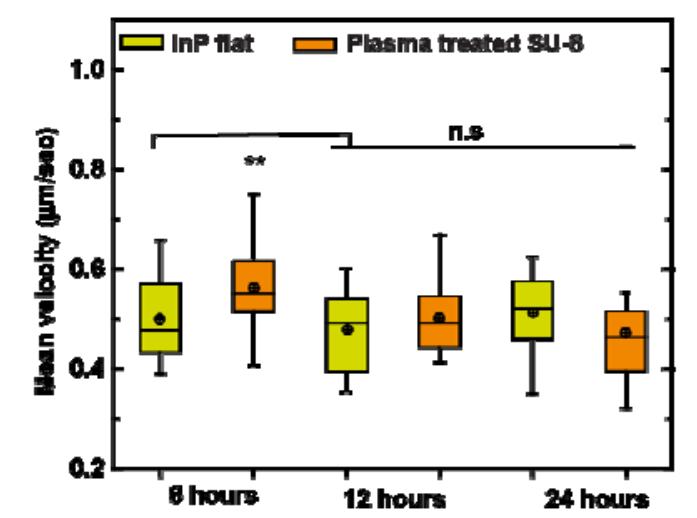

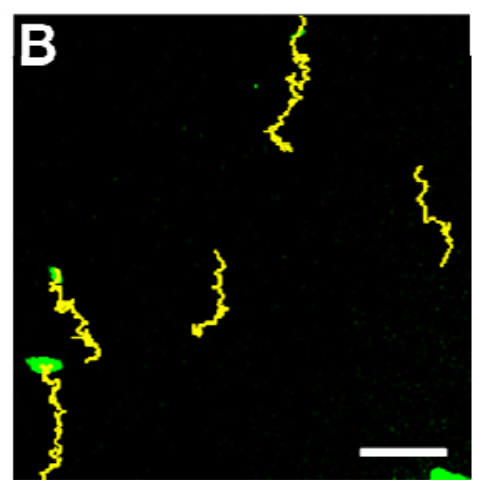

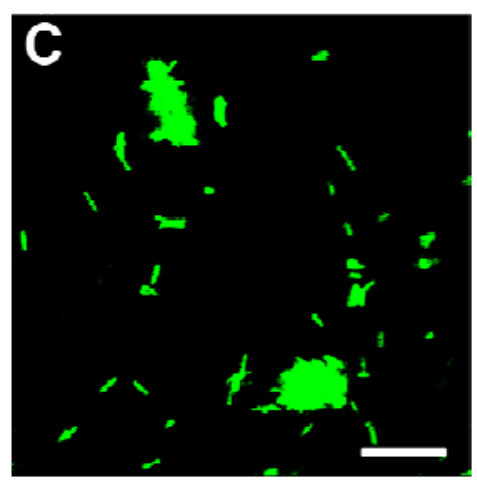

E

Plasme treated sU-8

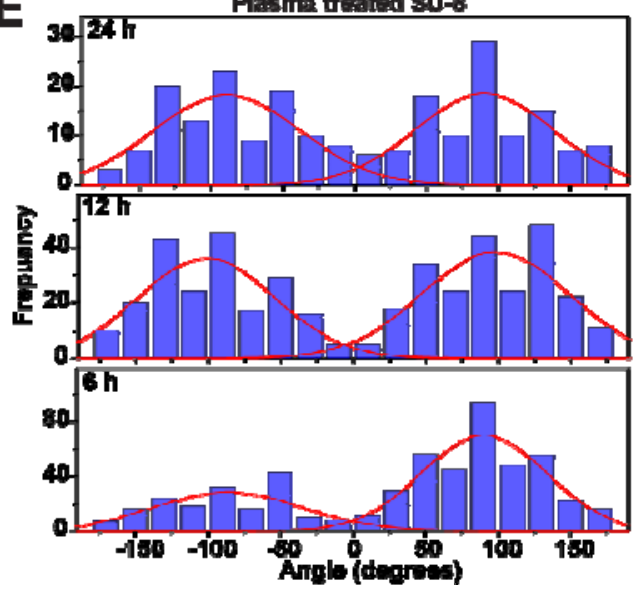

Figure 2. $X$. fastidiosa single cell motility changes on different surface physicochemical properties of samples. Trajectory of moving $X$. fastidiosa single cells on (A) InP (B) plasma treated SU-8 and (C) pristine SU-8 (no trackable motile cells) from time lapse CLSM videos for 3 min tracking after $6 \mathrm{~h}$ of growth. Yellow lines indicate cell trajectory. Scale bars: $20 \mu \mathrm{m}$. (D) Mean velocity of single cell movement on hydrophilic InP and plasma treated SU-8 surfaces after 6, 12 and $24 \mathrm{~h}$ growth (from $\mathrm{N}=25$ tracks for each). (E) Distribution of angle of each segment of the trajectories obtained from xy coordinates of the tracks on plasma-treated SU-8 samples after 6,12 and $24 \mathrm{~h}$ growth; red lines indicate Gaussian fitting to positive and negative ranges of angle distribution.

Moreover, cell trajectories in plasma treated SU-8 surfaces after $6 \mathrm{~h}$ of growth (Fig. 3A) showed significantly longer displacement values $(\sim 15 \mu \mathrm{m})$ than all other cases $(6,12$ and $24 \mathrm{~h}$ ) of growth on InP and, 12 and $24 \mathrm{~h}$ growth on plasma-treated SU-8 samples ( 7 $\mu \mathrm{m})$. The distinct straighter orientations, larger mean velocity and displacement of trajectories of plasma-treated SU-8 after $6 \mathrm{~h}$ growth could be due to the larger density of surface carboxyl groups, and the hydrophilic nature of the sample; since plasma was applied just before inoculation, the activated carboxyl groups may have a role in cell motility. However, after 12 and $24 \mathrm{~h}$ growth, the motility drops on the plasma-treated 
samples, most likely due to surface conditioning by both growth medium and continuous EPS (Extracellular Polymeric Substance) secretion[32] which covers the surface and, consequently, stabilize the carboxylic groups. To further confirm whether the carboxyl functional group is critical for such exquisite cell movement, InP samples functionalized with carboxylic groups (as explained in Methods section) were studied. Interestingly and in agreement with our hypothesis, the single cells trajectories on InP carboxylic surface are also straighter, with longer displacements for the $6 \mathrm{~h}$ growth period (Fig. S4).

We further investigate the possible displacement of single cells in a more sensitive way by calculating averaged MSD as a function of time for all three-growth times of plasma-treated and InP samples, as shown in Fig. 3B and C, respectively. The log-log plot of MSD describes the anomalous diffusion model and the slope of the plot can indicate the characteristics of a cell trajectory[61]. For random diffusion, the MSD is expected to show slope $\alpha=1$, while slope $=2$ is related to ballistic motion[62]. Therefore, cell trajectories with MSD slopes $\alpha>1$ (superdiffusive process) indicate persistent movement and slopes $\alpha$ $<1$ (subdiffusive process) suggest confined movement[61,63,64]. Indeed, the MSD curves of the plasma-treated samples indicate two distinct types of trajectories observed on the samples: persistent (slope $=1.18$ for 6 h growth: Fig. 3B) and confined (slope $\approx 0.8$ for 12 $\& 24$ h growth; Fig 3B). On the other hand, the MSD values for InP samples for all growth times indicate confined motion (slope $\approx 0.8$; Fig. 3C) except for the carboxylated InP surface for $6 \mathrm{~h}$ growth which indicates persistent motion (slope=1.27; Fig. 3C). Moreover, both plasma-treated SU-8 and carboxylated InP samples for $6 \mathrm{~h}$ growth time present MSD values one order of magnitude larger than their counterparts in Figures $3 \mathrm{~B}$ and $3 \mathrm{C}$, respectively.

Twitching motility occurs by pili elongation, surface adhesion and retraction[35,65], with type IV pili of $X$. fastidiosa typically found at one of the cell poles. The pili are composed of pilin proteins in which the pilus core is filled by amino-terminal $\alpha$-helices and the outer surface is formed by carboxyl terminal domains[37]. In the case of carboxylic functional surfaces, a repulsive molecular interaction between $X$. fastidiosa pili and surface carboxylic groups most likely makes the surface less resistant against motion, also 
providing a longer distance exploration along the trajectory. Particularly, the larger slope of MSD curves $(\alpha>1)$ for the carboxylated samples until $6 \mathrm{~h}$ growth time would indicate the relatively smooth surface detachment and successive re-attachment of pili. Conrad et al. distinguish walking and crawling motions of Pseudomonas aeruginosa based on the MSD plots[63]. Regarding X. fastidiosa twitching motility, a previous study exhibit cell trajectories oriented towards upstream flow under fluidic conditions while random orientation of trajectories has been observed under no-fluidic conditions[35]. However, our study shows that surface chemistry can modify the bacterial behavior, as we confirmed the characteristics of persistent (carboxylated surface until $6 \mathrm{~h}$ ) and confined (all other surfaces) crawling motion of $X$. fastidiosa present in our SU-8 samples, under no-flow conditions.
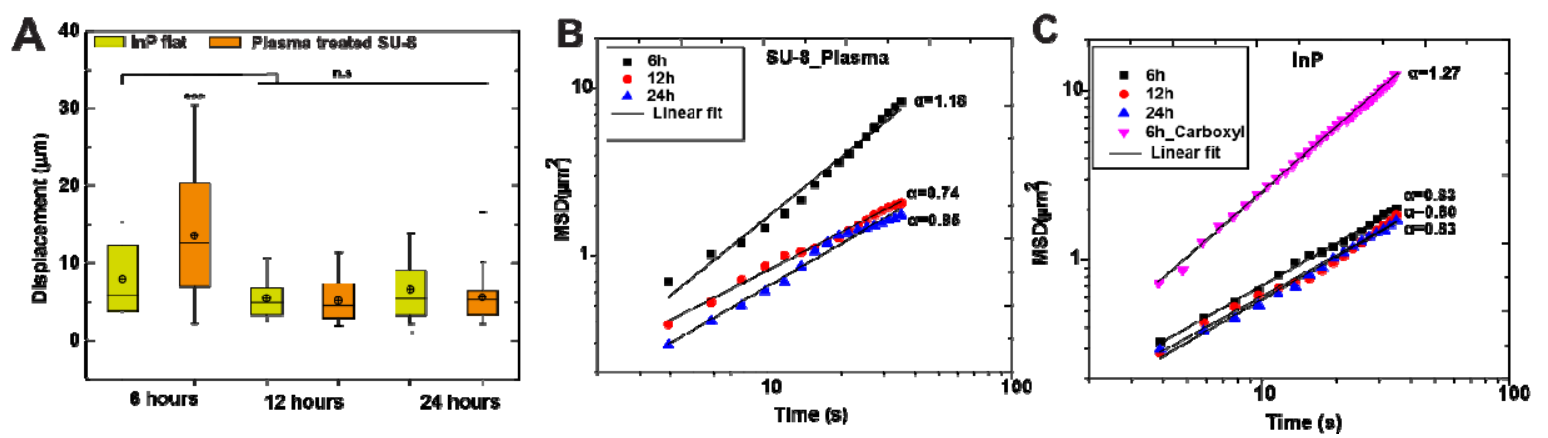

Figure 3. Quantifying displacement indicators of single cell trajectories on different surfaces. (A) Net displacement values for single cell movement on InP and plasma treated SU-8 surfaces after 6, 12 and 24 h growth (from $\mathrm{N}=25$ tracks for each). (B) Average of mean square displacement (MSD) with function of time of single cell movement on plasma treated SU-8 and (C) InP surfaces after 6, 12 and 24 h of growth along with and carboxylic group functionalized $\mathrm{InP}$ after $6 \mathrm{~h}$ growth; Black line indicates linear fit and $\alpha$ is the corresponding slope value (from $\mathrm{N}=10$ tracks for each). 

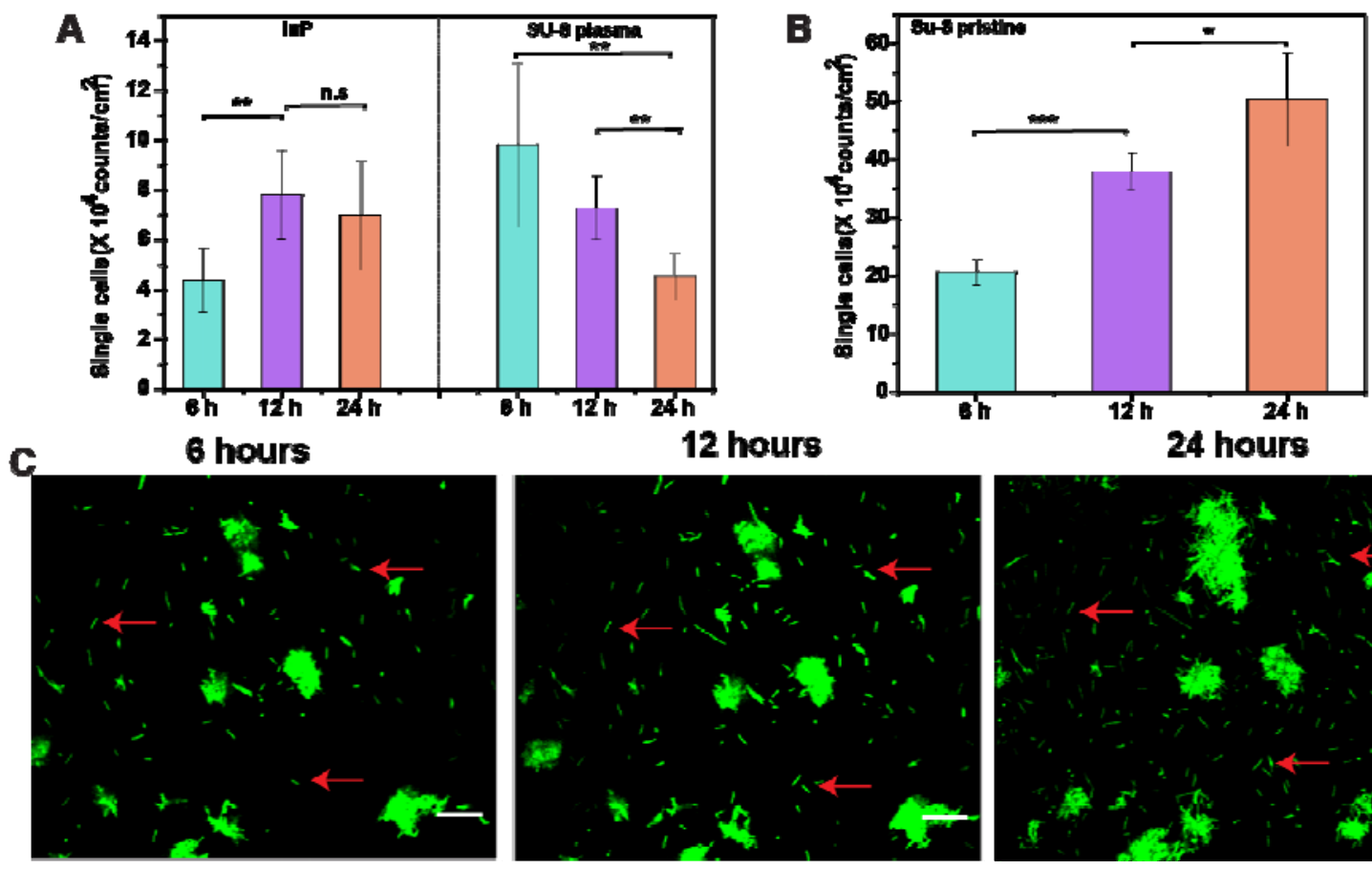

2 hours

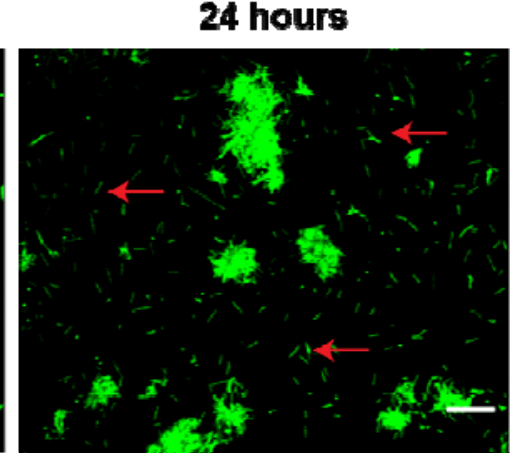

Figure 4. Bacterial adhesion on different surface properties (A) Number of single cells that exhibit motion or remain adhered on InP and plasma-treated SU-8 surfaces after 24 h growth (from $\mathrm{N}=7$ images each). (B) Number of single cells adhered on pristine SU-8 surfaces after 6, 12 and 24h growth (from $\mathrm{N}=7$ images each). (C) In vitro CLSM images of bacterial adhesion on same area of a pristine SU-8 sample after 6, 12 and 24h growth. Red arrows point the few single cells firmly adhered to the same location of the surface, along the whole period of growth. Color histogram is adjusted so that single cells can be visualized; Scale bar:20 $\mu \mathrm{m}$.

Since the distinct characteristics of bacterial motility are observed with different surfaces and growth times, we further compared how the number of single cells changed with respect to the surface properties of the samples. Single cells on the surface were counted from confocal images for each 6, 12, and $24 \mathrm{~h}$ growth (Fig. 4 A, B). The results show InP surface has increasing number of single cells over 6 and $12 \mathrm{~h}$ growth; after $24 \mathrm{~h}$ growth, the number of cells remains almost stable. In contrast, single cells on the plasmatreated SU-8 surfaces have gradually decreased over time (6-24h). This could be due to the lack of surface interactions and larger displacement of the cells in the initial growth time on the plasma treated SU-8 sample. In other words, the cells are vastly motile to explore the desired surface, but that ultimately leads to dispersal of cells on surface due to weaker cellsurface interactions. In fact, the increased hydrophilicity of plasma-treated samples should reduce the number of adhered bacteria compared to pristine SU-8 as per general 
thermodynamic theory[66]. Our results confirmed this prediction, as we observed about 5times larger number of individual attached cells to the pristine SU-8 surfaces after 6, 12 and 24h growth (Fig. 4B). Furthermore, more firmly-adhered single cells were observed for the pristine samples as indicated by arrows in the figure, showing single cells in the same surface location after 12 and $24 \mathrm{~h}$ of growth (Fig. 4C). Also, the fast adhesion (Supplementary Video S1) indicates the strongest cell interaction with pristine SU-8 surfaces. Such scenario could be more likely due to type IV pili interaction to the hydrophobic nature of such surfaces, and further facilitated by the strong interaction of hydrophobic $X$. fastidiosa cell surface[66,67]. This strong adhesion of type IV pili to hydrophobic surfaces is also reported for Pseudomonas aeruginosa[68]. Moreover, our observations agree qualitatively with previous results on Gram-negative Escherichia coli adherence to polymeric surfaces with contact angle of $90^{\circ}$ [69] and also with Gram-positive bacteria Micromonospora purpurea onto material surfaces with contact angle ranging from 54 to $130^{\circ}$ [70]. It is interesting to note that the present observation on the stronger and fast adhesion to pristine SU-8 surfaces provides some support to the previous hypothesis that $X$. fastidiosa bacterial cells acquired from plants are quickly adhesive once they contact the hydrophobic-in-nature cuticle surface of foreguts [71,72].


Figure 5. Bacterial colonization on distinct surface properties of samples. Comparison of (A) of microcolonies formed after 6, 12 and $24 \mathrm{~h}$ growth and (B) bacterial coverage percentage on the InP, pristine and plasma treated SU-8 surfaces after $24 \mathrm{~h}$ growth. $(\mathrm{N}=10$ images for each).

To determine how SU-8 surface properties influence bacterial growth, we next sought to quantify the microcolonies sizes and coverage area on the three different samples from the recorded in vitro CLSM images (Fig. 4C and Supplementary Fig. S5). The 
results confirm that larger microcolonies sizes occur on InP surfaces (Fig. 5A) for all growth times (6-24h), when compared to the other two surfaces. Especially, the higher bacterial coverage of $X$. fastidiosa after $24 \mathrm{~h}$ growth (Fig. 5B) could be due to the large stiffness of the rigid InP surface; such a high colonization rate on rigid surfaces has been previously observed for several Gram-negative bacteria, including X. fastidiosa [73,74]. On the other hand, gradual growth of microcolonies, reaching up relatively large sizes over time, were observed for pristine SU-8 samples despite no trackable motile cells even after $24 \mathrm{~h}$ growth (Fig. 5A). This observation is also in agreement with previous reports stating that hydrophobic interactions are usually the strongest of all long-range noncovalent interactions and they play a significant role in cell adhesion and aggregation[75-77]. In contrast, the plasma-treated sample present microcolonies with smaller sizes (Fig. 5A) and no significant change in size for all growth times used here. Furthermore, the coverage area is significantly smaller (70-90 \%) when compared to pristine SU-8 and InP samples (Fig. 5B).

The interaction of bacterial cells with surface carboxylic groups and hydrophilic surface of plasma-treated surface affect both the attachment rate and colonization of bacteria, and the surface presents antifouling characteristics. However, apart from the characterized potential increase in hydrophilicity to the plasma-treated SU-8 surfaces, further investigation on surface potential changes of the different samples are also necessary to check whether it plays a role in observed bacterial behavior. Although surface motility can be a crucial strategy in bacterial growth whereby bacteria seek nutrients and enable new colonies[39], the present results emphasize this mechanism by which the necessity of the affinity of pili to the substrate is required. Overall, the study provides comprehensive understanding of bacterial-SU-8 surface interaction which could lead to design effective strategies for the fabrication of SU-8 based various unique devices for biomedical applications[8-11,14].

\section{Conclusion}

In summary, our study elucidates the nanoscale surface changes of SU-8 thin films governed by wettability and surface carboxylic groups and how such properties influence bacterial motility, adhesion, and subsequent colonization in a spatiotemporal manner. The 
enhancement of the motility and direction of $X$. fastidiosa single cells on carboxylated surfaces during initial stages of growth has been observed. Particularly, the striking difference in cell trajectories and associated MSD values emphasize the underlying bacterial pili-surface interaction via surface functional groups. Notably, the hydrophobic nature of pristine SU-8 surfaces leads to relatively strong bacterial adhesion and larger number of microcolonies despite no observable motile cells. Conversely, the hydrophilic surface of plasma treated SU-8 samples exhibits significantly lower number of surface adhered single cells and about 70\% lower bacterial coverage than the pristine SU-8 surfaces. Moreover, this study improves the current understanding of the role of surface functional groups and wettability on bacteria-surface interaction and thereby create strategies to prevent microbial adhesion and consequently, biofilm development of pathogenic species. Nevertheless, the present results warrant further biophysical investigation on how efficiently the different motility mechanisms can be deployed in view of type IV pili coordination and interaction with respect to surface properties changes. Further understanding of such bacterial-SU-8 interaction should lead to developing surfaces that can be tuned to adsorb or reject cell types, and thus design novel biological systems.

\section{ACKNOWLEDGEMENTS}

The authors would like to thank Dr. Richard Janissen (TU Delft, Netherlands) for fruitful discussions. The authors are greatly indebted to Ursula F.S. Roggero (FEEC, UNICAMP) and Vitor Pelegati (IFGW, UNICAMP) for their assistance during sample preparation and confocal microscope access, respectively. This work was financially supported by the Brazilian agencies CNPq (441799/2016-7 and 429326/2018-1) and FAPESP (Grants number 2013/10957-0 and 2019/07616-3). S.A. and A.M.S acknowledge FAPESP (2017/14398-7) and CNPq, respectively, for funding their scholarships. The authors thank INFABIC/UNICAMP (FAPESP: 2014/50938-8, CNPq: 465699/2014-6), Semiconductor Component and Nanotechnology Center (CCSNano, UNICAMP) and the Device Research Laboratory (IFGW, UNICAMP) for granting access to their facilities.

\section{References}

[1] S. Keller, G. Blagoi, M. Lillemose, D. Haefliger, A. Boisen, Processing of thin SU-8 
films, J. Micromechanics Microengineering. 18 (2008).

https://doi.org/10.1088/0960-1317/18/12/125020.

[2] S. Arscott, SU-8 as a material for lab-on-a-chip-based mass spectrometry, Lab Chip. 14 (2014) 3668-3689. https://doi.org/10.1039/c4lc00617h.

[3] A. Del Campo, C. Greiner, SU-8: A photoresist for high-aspect-ratio and 3D submicron lithography, J. Micromechanics Microengineering. 17 (2007) R81. https://doi.org/10.1088/0960-1317/17/6/R01.

[4] G. Blagoi, S. Keller, A. Johansson, A. Boisen, M. Dufva, Functionalization of SU-8 photoresist surfaces with IgG proteins, Appl. Surf. Sci. 255 (2008) 2896-2902. https://doi.org/10.1016/j.apsusc.2008.08.089.

[5] S. Anbumani, A.M. da Silva, U.F.S. Roggero, A.M.P.A. Silva, H.E. HernándezFigueroa, M.A. Cotta, Oxygen plasma-enhanced covalent biomolecule immobilization on SU-8 thin films: A stable and homogenous surface biofunctionalization strategy, Appl. Surf. Sci. 553 (2021) 149502. https://doi.org/10.1016/j.apsusc.2021.149502.

[6] I.A. Grimaldi, G. Testa, G. Persichetti, F. Loffredo, F. Villani, R. Bernini, Plasma functionalization procedure for antibody immobilization for SU-8 based sensor, Biosens. Bioelectron. 86 (2016) 827-833. https://doi.org/10.1016/j.bios.2016.07.090.

[7] J.C. Ramirez, J.N. Schianti, D.E.P. Souto, L.T. Kubota, H.E. Hernandez-Figueroa, L.H. Gabrielli, Dielectric barrier discharge plasma treatment of modified SU-8 for biosensing applications, Biomed. Opt. Express. 9 (2018) 2168.

https://doi.org/10.1364/boe.9.002168.

[8] Y. Xin, G. Pandraud, L. Otten, Y. Zhang, P. French, Surface Functionalization of SU-8 Vertical Waveguide for Biomedical Sensing: Bacteria Diagnosis, Proceedings. 2 (2018) 1081. https://doi.org/10.3390/proceedings2131081.

[9] S.G. Dastider, A. Abdullah, I. Jasim, N.S. Yuksek, M. Dweik, M. Almasri, Low concentration E. coli O157:H7 bacteria sensing using microfluidic MEMS biosensor, Rev. Sci. Instrum. 89 (2018) 125009. https://doi.org/10.1063/1.5043424.

[10] T.F. Kong, X. Shen, Marcos, C. Yang, I.H. Ibrahim, Dielectrophoretic trapping and impedance detection of Escherichia coli, Vibrio cholera, and Enterococci bacteria, Biomicrofluidics. 14 (2020) 054105. https://doi.org/10.1063/5.0024826. 
[11] R. Mathew, A. Ravi Sankar, A Review on Surface Stress-Based Miniaturized Piezoresistive SU-8 Polymeric Cantilever Sensors, Nano-Micro Lett. 10 (2018) 141. https://doi.org/10.1007/s40820-018-0189-1.

[12] B.F.E. Matarèse, P.L.C. Feyen, A. Falco, F. Benfenati, P. Lugli, J.C. Demello, Use of SU8 as a stable and biocompatible adhesion layer for gold bioelectrodes, Sci. Rep. 8 (2018) 1-12. https://doi.org/10.1038/s41598-018-21755-6.

[13] S.J. Park, H. Bae, J. Kim, B. Lim, J. Park, S. Park, Motility enhancement of bacteria actuated microstructures using selective bacteria adhesion, Lab Chip. 10 (2010) 1706-1711. https://doi.org/10.1039/c000463d.

[14] Z. Chen, J.-B. Lee, Biocompatibility of SU-8 and Its Biomedical Device Applications, Micromachines 2021, Vol. 12, Page 794. 12 (2021) 794. https://doi.org/10.3390/MI12070794.

[15] K.Y. Lee, N. LaBianca, S.A. Rishton, S. Zolgharnain, J.D. Gelorme, J. Shaw, T.H.P. Chang, Micromachining applications of a high resolution ultrathick photoresist, J.

Vac. Sci. Technol. B Microelectron. Nanom. Struct. 13 (1995) 3012-3016. https://doi.org/10.1116/1.588297.

[16] S. Chung, S. Park, Effects of temperature on mechanical properties of SU-8 photoresist material, J. Mech. Sci. Technol. 27 (2013) 2701-2707. https://doi.org/10.1007/s12206-013-0714-6.

[17] K.S. Beckwith, S.P. Cooil, J.W. Wells, P. Sikorski, Tunable high aspect ratio polymer nanostructures for cell interfaces, Nanoscale. 7 (2015) 8438-8450. https://doi.org/10.1039/c5nr00674k.

[18] R. Martinez-Duarte, M.J. Madou, SU-8 photolithography and its impact on microfluidics, in: Microfluid. Nanofluidics Handb. Fabr. Implementation, Appl., CRC Press, 2016: pp. 231-268. https://doi.org/10.1201/b11188-12.

[19] J. Azeredo, N.F. Azevedo, R. Briandet, N. Cerca, T. Coenye, A.R. Costa, M. Desvaux, G. Di Bonaventura, M. Hébraud, Z. Jaglic, M. Kačániová, S. Knøchel, A. Lourenço, F. Mergulhão, R.L. Meyer, G. Nychas, M. Simões, O. Tresse, C. Sternberg, Critical review on biofilm methods, Crit. Rev. Microbiol. 43 (2017) 313351. https://doi.org/10.1080/1040841X.2016.1208146.

[20] H.C. Flemming, J. Wingender, U. Szewzyk, P. Steinberg, S.A. Rice, S. Kjelleberg, 
Biofilms: An emergent form of bacterial life, Nat. Rev. Microbiol. 14 (2016) 563575. https://doi.org/10.1038/nrmicro.2016.94.

[21] Y. Cheng, G. Feng, C.I. Moraru, Micro- and Nanotopography Sensitive Bacterial Attachment Mechanisms: A Review, Front. Microbiol. 10 (2019) 10. https://doi.org/10.3389/fmicb.2019.00191.

[22] C.R. Arciola, D. Campoccia, L. Montanaro, Implant infections: Adhesion, biofilm formation and immune evasion, Nat. Rev. Microbiol. 16 (2018) 397-409. https://doi.org/10.1038/s41579-018-0019-y.

[23] B.R. Wucher, T.M. Bartlett, M. Hoyos, K. Papenfort, A. Persat, C.D. Nadell, Vibrio cholerae filamentation promotes chitin surface attachment at the expense of competition in biofilms, Proc. Natl. Acad. Sci. U. S. A. 116 (2019) 14216-14221. https://doi.org/10.1073/pnas.1819016116.

[24] G.S. Lorite, C.M. Rodrigues, A.A. de Souza, C. Kranz, B. Mizaikoff, M.A. Cotta, The role of conditioning film formation and surface chemical changes on Xylella fastidiosa adhesion and biofilm evolution, J. Colloid Interface Sci. 359 (2011) 289_ 295. https://doi.org/10.1016/j.jcis.2011.03.066.

[25] H. Gu, D. Ren, Materials and surface engineering to control bacterial adhesion and biofilm formation: A review of recent advances, Front. Chem. Sci. Eng. 8 (2014) 20-33. https://doi.org/10.1007/s11705-014-1412-3.

[26] Y.J. Oh, E.S. Khan, A. Del Campo, P. Hinterdorfer, B. Li, Nanoscale Characteristics and Antimicrobial Properties of (SI-ATRP)-Seeded Polymer Brush Surfaces, ACS Appl. Mater. Interfaces. 11 (2019) 29312-29319. https://doi.org/10.1021/acsami.9b09885.

[27] B.J. Pedimonte, T. Moest, T. Luxbacher, C. Von Wilmowsky, T. Fey, K.A. Schlegel, P. Greil, Morphological zeta-potential variation of nanoporous anodic alumina layers and cell adherence, Acta Biomater. 10 (2014) 968-974. https://doi.org/10.1016/J.ACTBIO.2013.09.023.

[28] M. Ventre, P.A. Netti, Engineering Cell Instructive Materials to Control Cell Fate and Functions through Material Cues and Surface Patterning, ACS Appl. Mater. Interfaces. 8 (2016) 14896-14908. https://doi.org/10.1021/acsami.5b08658.

[29] K. Anselme, P. Davidson, A.M. Popa, M. Giazzon, M. Liley, L. Ploux, The 
interaction of cells and bacteria with surfaces structured at the nanometre scale, Acta Biomater. 6 (2010) 3824-3846. https://doi.org/10.1016/J.ACTBIO.2010.04.001.

[30] S. Anbumani, A.M. Da Silva, E.R. Fischer, M. De Souza E Silva, A.A.G. Von Zuben, H.F. Carvalho, A.A. De Souza, R. Janissen, M.A. Cotta, Controlled spatial organization of bacterial clusters reveals cell filamentation is vital for Xylella fastidiosa biofilm formation, BioRxiv. (2021) 2021.01.08.425936. https://doi.org/10.1101/2021.01.08.425936.

[31] M. Godefroid, A. Cruaud, J.C. Streito, J.Y. Rasplus, J.P. Rossi, Xylella fastidiosa: climate suitability of European continent, Sci. Rep. 9 (2019) 8844. https://doi.org/10.1038/s41598-019-45365-y.

[32] R. Janissen, D.M. Murillo, B. Niza, P.K. Sahoo, M.M. Nobrega, C.L. Cesar, M.L.A. Temperini, H.F. Carvalho, A.A. De Souza, M.A. Cotta, Spatiotemporal distribution of different extracellular polymeric substances and filamentation mediate Xylella fastidiosa adhesion and biofilm formation, Sci. Rep. 5 (2015) 9856. https://doi.org/10.1038/srep09856.

[33] T.M. Voegel, J.G. Warren, A. Matsumoto, M.M. Igo, B.C. Kirkpatrick, Localization and characterization of Xylella fastidiosa haemagglutinin adhesins, Microbiology. 156 (2010) 2172-2179. https://doi.org/10.1099/mic.0.037564-0.

[34] A. Matsumoto, S.L. Huston, N. Killiny, M.M. Igo, XatA, an AT-1 autotransporter important for the virulence of Xylella fastidiosa Temecula1, Microbiologyopen. 1 (2012) 33-45. https://doi.org/10.1002/mbo3.6.

[35] Y. Meng, Y. Li, C.D. Galvani, G. Hao, J.N. Turner, T.J. Burr, H.C. Hoch, Upstream migration of Xylella fastidiosa via pilus-driven twitching motility, J. Bacteriol. 187 (2005) 5560-5567. https://doi.org/10.1128/JB.187.16.5560-5567.2005.

[36] L. De La Fuente, T.J. Burr, H.C. Hoch, Mutations in type I and type IV pilus biosynthetic genes affect twitching motility rates in Xylella fastidiosa, J. Bacteriol. 189 (2007) 7507-7510. https://doi.org/10.1128/JB.00934-07.

[37] L. Craig, K.T. Forest, B. Maier, Type IV pili: dynamics, biophysics and functional consequences, Nat. Rev. Microbiol. 17 (2019) 429-440. https://doi.org/10.1038/s41579-019-0195-4.

[38] R. Caserta, M.A. Takita, M.L. Targon, L.K. Rosselli-Murai, A.P. De Souza, L. 
Peroni, D.R. Stach-Machado, A. Andrade, C.A. Labate, E.W. Kitajima, M.A. Machado, A.A. De Souza, Expression of xylella fastidiosa fimbrial and afimbrial proteins durine biofilm formation, Appl. Environ. Microbiol. 76 (2010) 4250-4259. https://doi.org/10.1128/AEM.02114-09.

[39] L. Ni, S. Yang, R. Zhang, Z. Jin, H. Chen, J.C. Conrad, F. Jin, Bacteria differently deploy type-IV pili on surfaces to adapt to nutrient availability, Npj Biofilms Microbiomes. 2 (2016) 1-10. https://doi.org/10.1038/npjbiofilms.2015.29.

[40] R. Janissen, P.K. Sahoo, C.A. Santos, A.M. Da Silva, A.A.G. Von Zuben, D.E.P. Souto, A.D.T. Costa, P. Celedon, N.I.T. Zanchin, D.B. Almeida, D.S. Oliveira, L.T. Kubota, C.L. Cesar, A.P.D. Souza, M.A. Cotta, InP Nanowire Biosensor with Tailored Biofunctionalization: Ultrasensitive and Highly Selective Disease Biomarker Detection, Nano Lett. 17 (2017) 5938-5949. https://doi.org/10.1021/acs.nanolett.7b01803.

[41] D.L. Williams, A.T. Kuhn, M.A. Amann, M.B. Hausinger, M.M. Konarik, E.I. Nesselrode, Computerised measurement of contact angles, Galvanotechnik. 101 (2010) 2502-2512.

[42] B. Niza, H.D. Coletta-Filho, M. V. Merfa, M.A. Takita, A.A. de Souza, Differential colonization patterns of Xylella fastidiosa infecting citrus genotypes, Plant Pathol. 64 (2015) 1259-1269. https://doi.org/10.1111/ppa.12381.

[43] M.J. Davis, W.J. French, N.W. Schaad, Axenic culture of the bacteria associated with phony disease of peach and plum leaf scald, Curr. Microbiol. 6 (1981) 309-314. https://doi.org/10.1007/BF01566883.

[44] J.Y. Tinevez, N. Perry, J. Schindelin, G.M. Hoopes, G.D. Reynolds, E. Laplantine, S.Y. Bednarek, S.L. Shorte, K.W. Eliceiri, TrackMate: An open and extensible platform for single-particle tracking, Methods. 115 (2017) 80-90. https://doi.org/10.1016/j.ymeth.2016.09.016.

[45] J. Schindelin, I. Arganda-Carreras, E. Frise, V. Kaynig, M. Longair, T. Pietzsch, S. Preibisch, C. Rueden, S. Saalfeld, B. Schmid, J.Y. Tinevez, D.J. White, V. Hartenstein, K. Eliceiri, P. Tomancak, A. Cardona, Fiji: An open-source platform for biological-image analysis, Nat. Methods. 9 (2012) 676-682. https://doi.org/10.1038/nmeth.2019. 
[46] M. Manich, A. Boquet-Pujadas, S. Dallongeville, N. Guillen, J.-C. Olivo-Marin, A Protocol to Quantify Cellular Morphodynamics: From Cell Labelling to Automatic Image Analysis, in: Eukaryome Impact Hum. Intest. Homeost. Mucosal Immunol., Springer International Publishing, 2020: pp. 351-367. https://doi.org/10.1007/978-3030-44826-4_25.

[47] F. Walther, T. Drobek, A.M. Gigler, M. Hennemeyer, M. Kaiser, H. Herberg, T. Shimitsu, G.E. Morfill, R.W. Stark, Surface hydrophilization of SU-8 by plasma and wet chemical processes, Surf. Interface Anal. 42 (2010) 1735-1744. https://doi.org/10.1002/sia.3515.

[48] F. Walther, P. Davydovskaya, S. Zürcher, M. Kaiser, H. Herberg, A.M. Gigler, R.W. Stark, Stability of the hydrophilic behavior of oxygen plasma activated SU-8, J. Micromechanics Microengineering. 17 (2007) 524-531. https://doi.org/10.1088/0960-1317/17/3/015.

[49] P.K. Sahoo, R. Janissen, M.P. Monteiro, A. Cavalli, D.M. Murillo, M. V. Merfa, C.L. Cesar, H.F. Carvalho, A.A. De Souza, E.P.A.M. Bakkers, M.A. Cotta, Nanowire arrays as cell force sensors to investigate adhesin-enhanced holdfast of single cell bacteria and biofilm stability, Nano Lett. 16 (2016) 4656-4664. https://doi.org/10.1021/acs.nanolett.6b01998.

[50] A.M. da Silva, P.K. Sahoo, A. Cavalli, A.A. de Souza, E.P.A.M. Bakkers, C.L. Cesar, R. Janissen, M.A. Cotta, Nanowire Arrays as Force Sensors with SuperResolved Localization Position Detection: Application to Optical Measurement of Bacterial Adhesion Forces, Small Methods. 2 (2018) 1700411. https://doi.org/10.1002/smtd.201700411.

[51] S. Reiche, R. Blume, X.C. Zhao, D. Su, E. Kunkes, M. Behrens, R. Schlögl, Reactivity of mesoporous carbon against water - An in-situ XPS study, Carbon N. Y. 77 (2014) 175-183. https://doi.org/10.1016/j.carbon.2014.05.019.

[52] S. Biniak, G. Szymański, J. Siedlewski, A. Światkoski, The characterization of activated carbons with oxygen and nitrogen surface groups, Carbon N. Y. 35 (1997) 1799-1810. https://doi.org/10.1016/S0008-6223(97)00096-1.

[53] P.G. Ren, D.X. Yan, X. Ji, T. Chen, Z.M. Li, Temperature dependence of grapheme oxide reduced by hydrazine hydrate, Nanotechnology. 22 (2011). 
https://doi.org/10.1088/0957-4484/22/5/055705.

[54] S. Stankovich, D.A. Dikin, R.D. Piner, K.A. Kohlhaas, A. Kleinhammes, Y. Jia, Y. Wu, S.B.T. Nguyen, R.S. Ruoff, Synthesis of graphene-based nanosheets via chemical reduction of exfoliated graphite oxide, Carbon N. Y. 45 (2007) 1558-1565. https://doi.org/10.1016/j.carbon.2007.02.034.

[55] F. Perrozzi, S. Prezioso, M. Donarelli, F. Bisti, P. De Marco, S. Santucci, M. Nardone, E. Treossi, V. Palermo, L. Ottaviano, Use of optical contrast to estimate the degree of reduction of graphene oxide, J. Phys. Chem. C. 117 (2013) 620-625. https://doi.org/10.1021/jp3069738.

[56] S. Kundu, Y. Wang, W. Xia, M. Muhler, Thermal stability and reducibility of oxygen-containing functional groups on multiwalled carbon nanotube surfaces: A quantitative high-resolution xps and TPD/TPR study, J. Phys. Chem. C. 112 (2008) 16869-16878. https://doi.org/10.1021/jp804413a.

[57] Y. Yamada, H. Yasuda, K. Murota, M. Nakamura, T. Sodesawa, S. Sato, Analysis of heat-treated graphite oxide by X-ray photoelectron spectroscopy, J. Mater. Sci. 48 (2013) 8171-8198. https://doi.org/10.1007/s10853-013-7630-0.

[58] A. Ganguly, S. Sharma, P. Papakonstantinou, J. Hamilton, Probing the thermal deoxygenation of graphene oxide using high-resolution in situ X-ray-based spectroscopies, J. Phys. Chem. C. 115 (2011) 17009-17019. https://doi.org/10.1021/jp203741y.

[59] H. Estrade-Szwarckopf, XPS photoemission in carbonaceous materials: A "defect" peak beside the graphitic asymmetric peak, Carbon N. Y. 42 (2004) 1713-1721. https://doi.org/10.1016/j.carbon.2004.03.005.

[60] P.M.T.M. Van Attekum, G.K. Wertheim, Excitonic effects in core-hole screening, Phys. Rev. Lett. 43 (1979) 1896-1898. https://doi.org/10.1103/PhysRevLett.43.1896.

[61] J. Liesveld, Stem Cell Mobilization, in: G. Klein, P. Wuchter (Eds.), Encycl. Cancer, Springer Berlin Heidelberg, Berlin, Heidelberg, 2015: pp. 4341-4344. https://doi.org/10.1007/978-3-662-46875-3_7222.

[62] J.C. Conrad, Physics of bacterial near-surface motility using flagella and type IV pili: Implications for biofilm formation, Res. Microbiol. 163 (2012) 619-629. 
https://doi.org/10.1016/j.resmic.2012.10.016.

[63] J.C. Conrad, M.L. Gibiansky, F. Jin, V.D. Gordon, D.A. Motto, M.A. Mathewson, W.G. Stopka, D.C. Zelasko, J.D. Shrout, G.C.L. Wong, Flagella and pili-mediated near-surface single-cell motility mechanisms in P. aeruginosa, Biophys. J. 100 (2011) 1608-1616. https://doi.org/10.1016/j.bpj.2011.02.020.

[64] J. Sjollema, H.C. Van Der Mei, C.L. Hall, B.W. Peterson, J. De Vries, L. Song, E.D.D. Jong, H.J. Busscher, J.J.T.M. Swartjes, Detachment and successive reattachment of multiple, reversibly-binding tethers result in irreversible bacterial adhesion to surfaces, Sci. Rep. 7 (2017). https://doi.org/10.1038/s41598-017-047038 .

[65] B. Maier, G.C.L. Wong, How Bacteria Use Type IV Pili Machinery on Surfaces, Trends Microbiol. 23 (2015) 775-788. https://doi.org/10.1016/J.TIM.2015.09.002.

[66] M. Katsikogianni, Y. Missirlis, Concise review of mechanisms of bacterial adhesion to biomaterials and of techniques used in estimating bacteria-material interactions, Eur. Cells Mater. 8 (2004) 37-57. https://doi.org/10.22203/eCM.v008a05.

[67] L. De La Fuente, T.J. Burr, H.C. Hoch, Autoaggregation of Xylella fastidiosa cells is influenced by type I and type IV pili, Appl. Environ. Microbiol. 74 (2008) 55795582. https://doi.org/10.1128/AEM.00995-08.

[68] A. Beaussart, A.E. Baker, S.L. Kuchma, S. El-Kirat-Chatel, G.A. O’Toole, Y.F. Dufrêne, Nanoscale Adhesion Forces of Pseudomonas aeruginosa Type IV Pili, ACS Nano. 8 (2014) 10723-10733. https://doi.org/10.1021/NN5044383.

[69] Y. Yuan, M.P. Hays, P.R. Hardwidge, J. Kim, Surface characteristics influencing bacterial adhesion to polymeric substrates, RSC Adv. 7 (2017) 14254-14261. https://doi.org/10.1039/c7ra01571b.

[70] X.Q. Dou, D. Zhang, C. Feng, L. Jiang, Bioinspired Hierarchical Surface Structures with Tunable Wettability for Regulating Bacteria Adhesion, ACS Nano. 9 (2015) 10664-10672. https://doi.org/10.1021/acsnano.5b04231.

[71] N. Killiny, R.P.P. Almeida, Factors Affecting the Initial Adhesion and Retention of the Plant Pathogen Xylella fastidiosa in the Foregut of an Insect Vector, Appl. Environ. Microbiol. 80 (2014) 420-426. https://doi.org/10.1128/AEM.03156-13.

[72] N. Killiny, R.P.P. Almeida, Xylella fastidiosa afimbrial adhesins mediate cell 
transmission to plants by leafhopper vectors, Appl. Environ. Microbiol. 75 (2009) 521-528. https://doi.org/10.1128/AEM.01921-08.

[73] G.S. Lorite, R. Janissen, J.H. Clerici, C.M. Rodrigues, J.P. Tomaz, B. Mizaikoff, C. Kranz, A.A. de Souza, M.A. Cotta, Surface Physicochemical Properties at the Micro and Nano Length Scales: Role on Bacterial Adhesion and Xylella fastidiosa Biofilm Development, PLoS One. 8 (2013) e75247.

https://doi.org/10.1371/journal.pone.0075247.

[74] S. Zheng, M. Bawazir, A. Dhall, H.-E. Kim, L. He, J. Heo, G. Hwang, Implication of Surface Properties, Bacterial Motility, and Hydrodynamic Conditions on Bacterial Surface Sensing and Their Initial Adhesion, Front. Bioeng. Biotechnol. 9 (2021) 82. https://doi.org/10.3389/fbioe.2021.643722.

[75] L. Xie, J. Wang, C. Shi, X. Cui, J. Huang, H. Zhang, Q. Liu, Q. Liu, H. Zeng, Mapping the Nanoscale Heterogeneity of Surface Hydrophobicity on the Sphalerite Mineral, J. Phys. Chem. C. 121 (2017) 5620-5628.

https://doi.org/10.1021/acs.jpcc.6b12909.

[76] D. Alsteens, E. Dague, P.G. Rouxhet, A.R. Baulard, Y.F. Dufrêne, Direct measurement of hydrophobic forces on cell surfaces using AFM, Langmuir. 23 (2007) 11977-11979. https://doi.org/10.1021/la702765c.

[77] C.J. van Oss, Hydrophobicity and hydrophilicity of biosurfaces, Curr. Opin. Colloid Interface Sci. 2 (1997) 503-512. https://doi.org/10.1016/S1359-0294(97)80099-4. 